\title{
Pb Correction Algorithms for Non-destructive Provenancing of Lead and Tin Glazed Slip Wares
}

\author{
Detlef Wilke \\ Dr. Wilke Management \& Consulting GmbH, D 30974 Wennigsen, Germany
}

Copyright $(2016$ by authors, all rights reserved. Authors agree that this article remains permanently open access under the terms of the Creative Commons Attribution License 4.0 International License

\begin{abstract}
Lead and tin glazed pottery is frequently contaminated with $\mathrm{Pb}$ abundances even on the non-glazed surfaces of vessels and fragments. Elevated lead concentrations result in $\mathrm{Pb}$ specific matrix absorption and spectral interference effects on several discriminative trace elements - $\mathrm{Ga}, \mathrm{Rb}$ and $\mathrm{Y}$ - which are important for fully non-destructive micro-chemical provenance based on portable $\mathrm{x}$-ray fluorescence (pXRF) analysis. Empirical Lachance-Traill type correction algorithms have been developed by simulating increasing $\mathrm{Pb}$ surface abundances on fired clay samples with lead acetate sprayed on $4.0 \mu \mathrm{m}$ polypropylene film. For paste surface layers with up to approximately $1 \% \mathrm{w} / \mathrm{w}$ elemental lead concentrations, full compensation could be achieved, as demonstrated for a representative production waster assemblage of early modern lead glazed slip ware (Weser ware). Since the number of discriminative minor and trace elements in portable and stationary XRF of pottery is at the limit, the development of robust empirical correction algorithms for lead based matrix effects and spectral interferences and the validation of the applied quantification software, respectively, is essential.
\end{abstract}

Keywords pXRF Compositional Analysis, Spectral Interference $\mathrm{Pb}, \mathrm{Ga}, \mathrm{Rb}, \mathrm{Y}$, Calibration Spiked Clay Standards

\section{Introduction}

Among the many applied tasks of geochemical trace element analysis is provenance of lithic archaeological remains, like the attempt to elucidate the production region or even place of ancient pottery found in an archaeological context. The basic concept of compositional provenance is the expectation, that natural lithic raw material deposits exhibit a more or less unique trace element pattern, which can be used for back-tracing of artefacts having been exchanged or traded over long distance $[1,2]$. In the case of ceramic produce potters may have used various local clays over time, but may also have added a certain amount of nonplastic, coarse or fine-grained temper to modify the technological properties of the resulting wares. Thus there are two possible sources of trace elements contributing to the final pattern in the fired sherd, clay and temper and its respective precursor minerals [3].

There is a growing demand for fully non-destructive analysis of archaeological material, both for conservational reasons but also for increased sample throughput, with portable XRF spectrometers presently being the only suitable instruments for micro-chemical ceramic paste analysis. It is not so much the field applicability which gives preference to pXRF devices as compared to micro-XRF, particle-induced $\mathrm{X}$-ray emission (PIXE) or micro-destructive laser ablation sampling, but the unrestricted access of the instrument window to study material of whatever size, and the larger "sample volume" which better accommodates the intrinsic heterogeneities of ceramic fabrics [4]. Since in non-destructive analysis the surface of the ceramic fragments cannot be rigorously cleaned from intentional as well as post-depositional modifications, particular care must been taken that the trace element composition of the paste is not distorted by any surficial modifications. In the case of salt and lead glazed pottery, glazed areas of fragments and vessels are precluded from non-destructive analysis. The glaze as such acts as a physical barrier for the element specific photons excited in the paste, with lead as a heavy element being a particularly potent photon absorber. However, in the case of lead glazed pottery even unglazed wall sides and biscuit fired dishes and bowls typically exhibit elevated $\mathrm{Pb}$ intensities, probably derived from lead volatilization during the firing process [5]. Diffusion of lead from the lead-alkali glaze towards the ceramic body during firing has also been hypothesized [6]. An additional source of surficial lead contamination of unglazed pottery may be acid leachates in production wasters, containing both glazed and unglazed wares, which are easily adsorbed to the surface of low-fired porous ceramics [7, 8]. As previously recognized [5] and further detailed below, surficial $\mathrm{Pb}$ contaminations strongly interfere with the analysis of the discriminative trace elements $\mathrm{Ga}, \mathrm{Rb}$ and $\mathrm{Y}$, and its accurate 
quantification depends on empirical $\mathrm{Pb}$ correction algorithms, since more generalized fundamental parameter based quantifications seam to fall short. Furthermore $\mathrm{Pb}$ specific photon absorption ("Pb matrix absorption") needs to be corrected for any other discriminative elements like $\mathrm{Ti}, \mathrm{Fe}$, $\mathrm{Sr}, \mathrm{Zr}$ and $\mathrm{Nb}$.

Typical North European early modern slip wares, dishes and flat bowls with inside lead glazed slip decoration, are shown in Figure 1. The fragment in Figure $1 \mathrm{~b}$ is a biscuit firing before lead glaze application from a workshop established around 1600 in Enkhuizen, The Netherlands, by a Dutch merchant, who intended to bypass the imports of prestigious Werra ware from the traditional German production region at the Werra River (several villages in the modern German states of Hesse, Thuringia and Lower Saxony) [9]. The unglazed outer wall and bottom parts of all fragments exhibit varying lead abundances.

\section{Methods}

A BRUKER Tracer III-SD portable XRF analyser with Rh tube placed in a benchtop stand has been employed. Per calibration sample $5-10$ replicate analyses have been acquired, and $2-4$ spots per ceramic fragment were analysed for $120 \mathrm{sec}$ each at a tube power of $40 \mathrm{kV}$ and $10.3 \mu \mathrm{A}$ with a $25 \mu \mathrm{m} \mathrm{Ti} / 300 \mu \mathrm{m} \mathrm{Al}$ beam filter. The BRUKER software
S1PXRF 3.8.30 operated with PC trigger was used for signal acquisition. Background stripping and Bayes peak deconvolution of spectra was conducted with ARTAX 7.4.0.0 (BRUKER). For distance correction of concave sherds the resulting net counts were ratioed to the $\mathrm{Rh} K \alpha 1,2$ peak (Rayleigh scatter of the Rh tube, [10]). For quantification the Rayleigh normalized net counts were converted into element mass fractions based on empirical calibration factors established with spiked fired clay samples (blank of a commercial clay, particle size $99.8 \%<63 \mu \mathrm{m}$, plus 4 concentrations each of $\mathrm{Ti}, \mathrm{Fe}, \mathrm{Ga}, \mathrm{Rb}, \mathrm{Sr}, \mathrm{Y}, \mathrm{Zr}$ and $\mathrm{Nb}$, respectively, fired for $2 \mathrm{hrs}$. at $800-850^{\circ} \mathrm{C}$ ) [4]. For $\mathrm{Pb}$ spraying on Prolene $4.0 \mu \mathrm{m}$ film and $\mathrm{Pb}$ spiking, reagent grade lead (II) acetate trihydrate, $\geq 99 \%$ (Sigma-Aldrich) has been used. Fe absorption/ enhancement as well as spectral interference of $\mathrm{Rb} K \beta / \mathrm{Y} \mathrm{K} \alpha$ and $\mathrm{Y} \mathrm{K} \beta / \mathrm{Nb} \mathrm{K} \alpha$ [4] was corrected with empirical element specific Lachance-Traill algorithms [11]. Peak overlap of $\mathrm{Sr} \mathrm{K} \beta$ on $\mathrm{Zr} \mathrm{K} \alpha$ in the concentration range found in the pottery assemblages was properly corrected by the ARTAX software. Gross validation of the spiking curves was conducted with 12 geochemical reference materials (SARM 1, 41, 42, 44, 45, 48, 50, 52 and 69, South African Bureau of Standards, and CGL 002, 006 and 007, Mongolia Central Geological Laboratory). All concentration data are $\mathrm{w} / \mathrm{w} \%$ of the elements. For data processing Excel, R and ggobi were used.

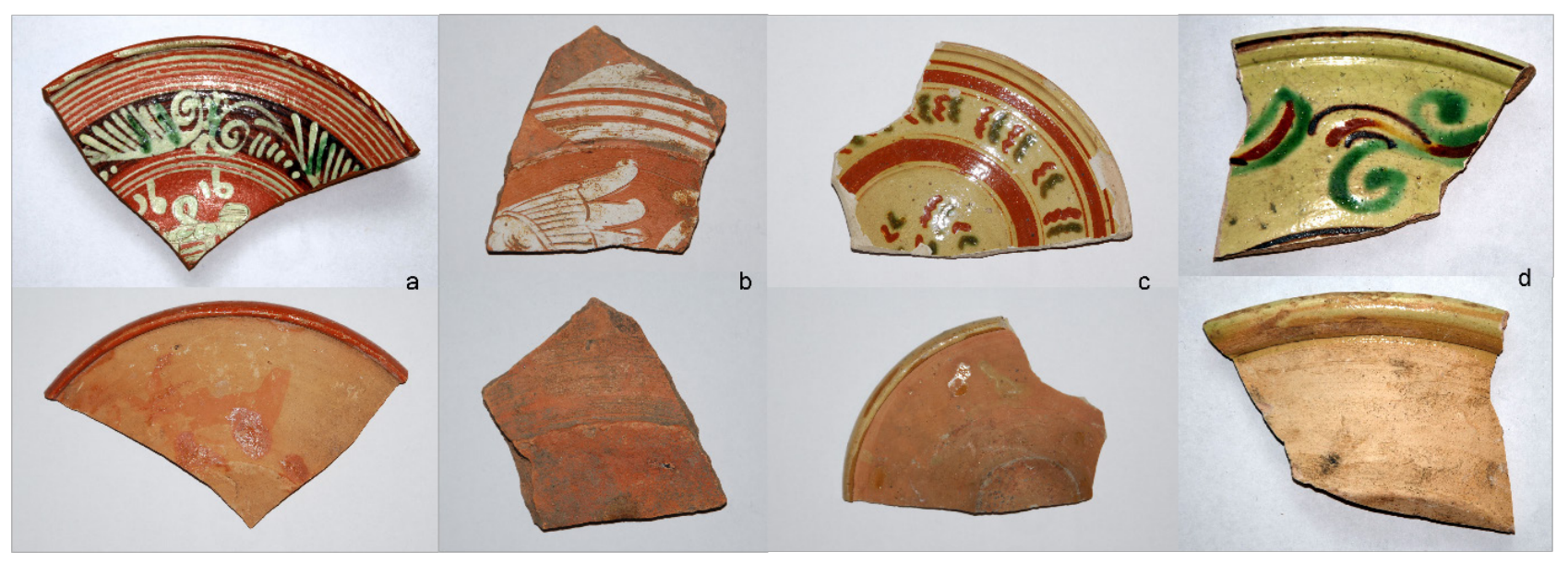

Figure 1. Fragments of early modern slip wares - above decorated insides, below unglazed outsides. (a) 17th century Werra ware, probably from Hesse or Lower Saxony, Germany. (b) 17th century Werra ware, biscuit firing, waster sherd from Enkhuizen, The Netherlands. (c) 17th century Weser ware, waster sherd from Voelksen, Lower Saxony, Germany. (d) 18th century Rhenish lead glazed slip ware, waster sherd from Frechen/Cologne, Germany.

\section{Results}

\subsection{Pb Matrix Absorption}

In the photon energy range $<40 \mathrm{keV} \mathrm{Pb}$ exhibits several $\mathrm{L}$ and $\mathrm{M}$ lines which differ in energy from 2.345 to $14.764 \mathrm{keV}$. The lower the energy of the line the more its fluorescence is absorbed by the clay matrix. To simulate surficial $\mathrm{Pb}(\mathrm{i})$, matrix/paste $\mathrm{Pb}$ (ii) und $\mathrm{Pb}$ glaze on the distal side (iii) fired clay samples have been analysed with placing a Prolene $4.0 \mu \mathrm{m}$ film sprayed with different lead acetate solutions between the instrument window and the sample (i), a set of fired clay samples spiked with lead acetate (ii), and a small lead weight has been placed on top of the measured sample (iii, sample 
thickness $3 \mathrm{~mm}$, Figures 2 and 3). The $\mathrm{Pb} \mathrm{M} \alpha$ peak having the lowest energy, is only visible upon $\mathrm{Pb}$ surface treatment. The $\mathrm{Pb} \mathrm{L} \alpha 1,2$ peak is attenuated much stronger than the $\mathrm{Pb} \mathrm{L} \beta 1,2$ and the $\mathrm{Pb} \mathrm{L} \gamma 1,2$ peaks. In the analysed pottery assemblages the unglazed wall side always exhibited a higher $\mathrm{Pb} \mathrm{L} \alpha 1,2$ than $\mathrm{Pb} \mathrm{L} \beta 1,2$ peak, indicating that surficial $\mathrm{Pb}$ contamination was the dominant source of $\mathrm{Pb}$ photon intensity in the XRF spectra.

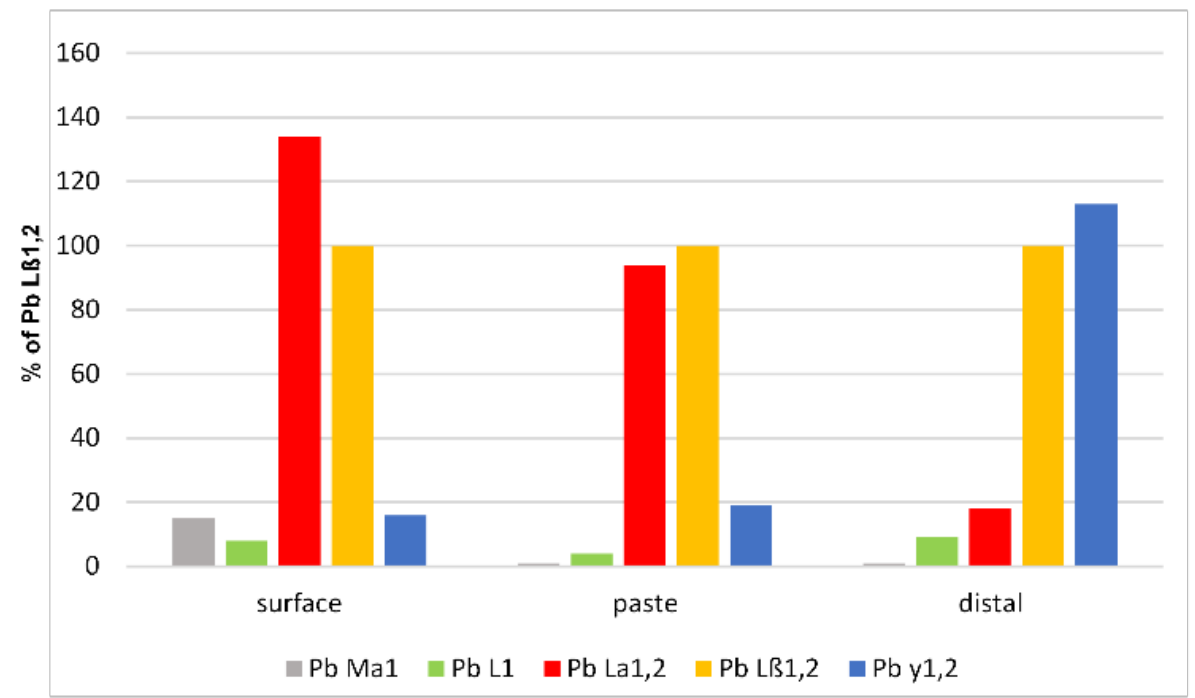

Figure 2. Attenuation of $\mathrm{Pb} \mathrm{L}$ and $\mathrm{M}$ shell photon energy depending on the information depth ( $\mathrm{Pb}$ net counts ratioed to the $\mathrm{Pb} \mathrm{L} \beta 1,2 \mathrm{peak}$ )

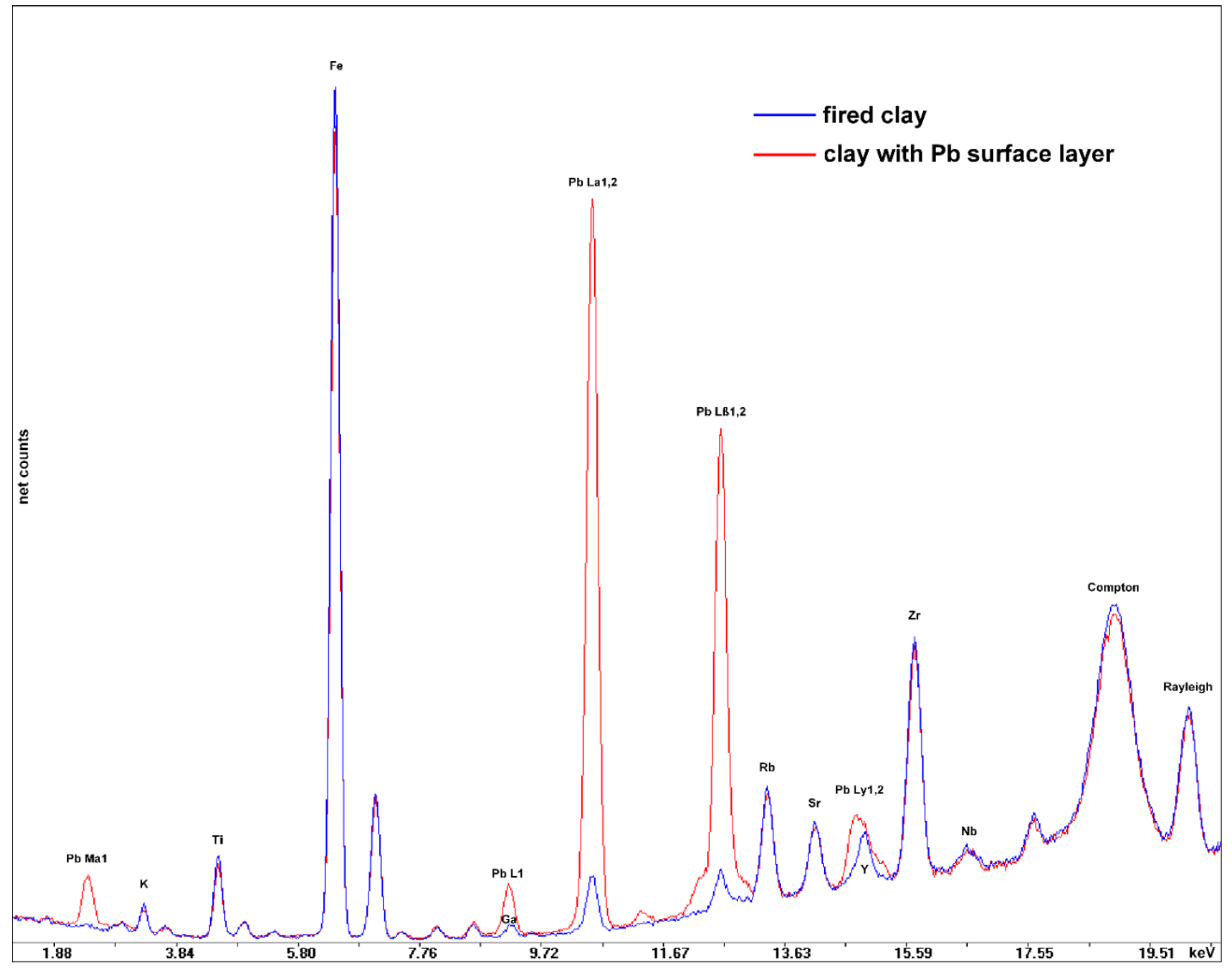

Figure 3. Spectral overlay of blank fired clay (blue line) and blank fired clay with lead acetate sprayed on Prolene $4.0 \mu \mathrm{m}$ film (red line) 
As shown in Figure 3 and Table 1 there is only modest photon absorption of the elements $\mathrm{Ti}, \mathrm{Fe}, \mathrm{Sr}, \mathrm{Zr}$ and $\mathrm{Nb}$ by surficial $\mathrm{Pb}$ abundance, which could be corrected with Lachance-Traill type influence coefficients (graph only shown for Zr, Figure 4). $\mathrm{The} \mathrm{Pb} \mathrm{L} \alpha 1,2$ peak has been used for $\mathrm{Pb}$ absorption correction because it provides the best counting statistics and does not interfere with any other element of interest (any significant As abundance hidden under the $\mathrm{Pb} \mathrm{L} \alpha 1,2$ peak would be recognized by its As $\mathrm{K} \beta 1$ peak at $11.725 \mathrm{keV}$ ). The influence coefficients for $\mathrm{Pb}$ absorption are setting specific, but are valid over an extended range of concentrations of the effected elements (i.e. for the mass fraction range typically found in pottery). Conversion of surficial $\mathrm{Pb}$ intensities into $\mathrm{w} / \mathrm{w}$ concentrations is semi-quantitative, since the $\mathrm{Pb}$ calibration like all other calibrations is based on homogenous elemental distribution in a fabric of infinite thickness. Surficial $\mathrm{Pb}$ intensities are thus given in arbitrary units $(\mathrm{Pb}$ net counts).

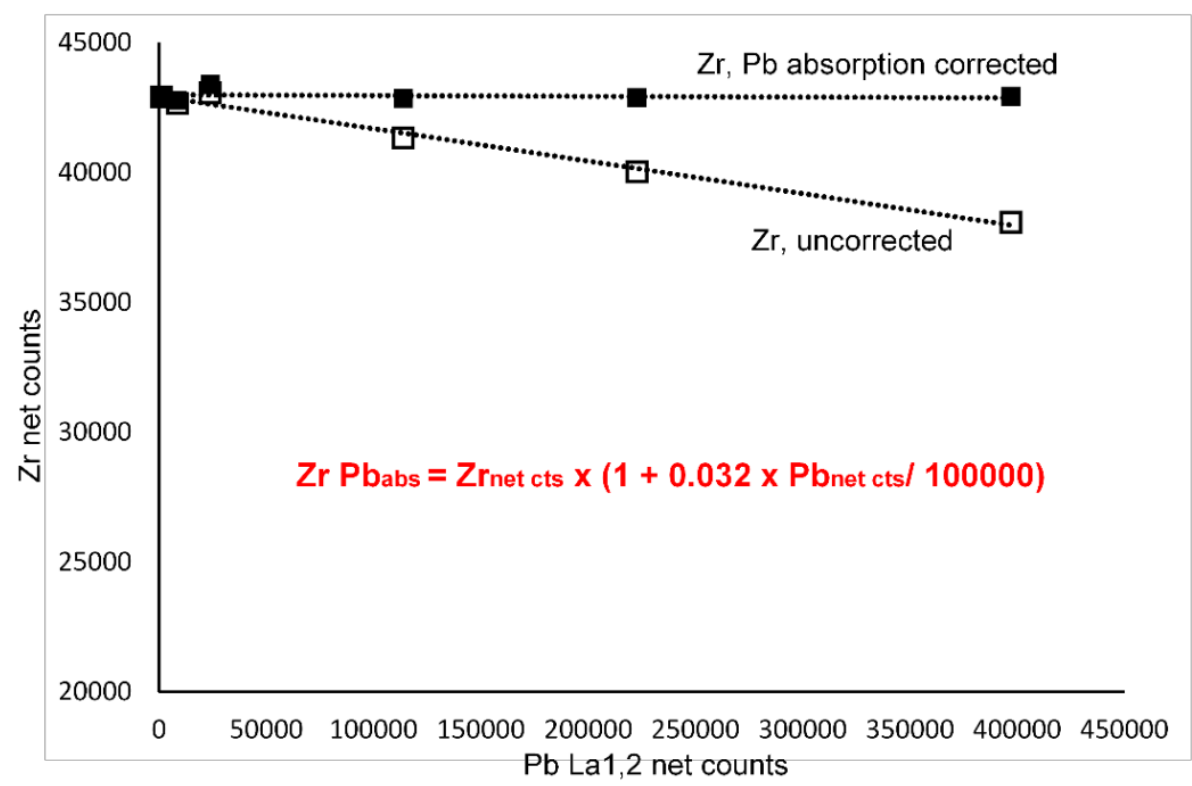

Figure 4. Correction of $\mathrm{Zr}$ net counts for surficial $\mathrm{Pb}$ absorption (lead acetate sprayed on Prolene film, $\mathrm{Zr}$ mass fraction of the clay blank $315 \pm 6$ ppm)

\subsection{Pb Spectral Interference}

By contrast the intensity peaks of $\mathrm{Ga}, \mathrm{Rb}$ and $\mathrm{Y}$ are strongly impacted by $\mathrm{Pb}$ peak overlap, and the ARTAX software does not properly correct for these interferences (Figures 3, 5, 6 and 7). The Pb L1 peak fully overlaps the Ga K $\alpha 1,2$ peak, and Ga mass fractions are strongly over reported with increasing surficial $\mathrm{Pb}$ abundances (Figure 5). The $\mathrm{Y} \mathrm{K \alpha 1,2}$ peak is flanked by the $\mathrm{Pb} \mathrm{L \gamma} 1$ and $\mathrm{Pb} \mathrm{L \gamma} 2$ peak, and the $\mathrm{Y}$ mass fractions are overreported as well (Figure 6). The $\mathrm{Rb} \mathrm{K} \alpha 1,2$ peak is least impacted, namely by a confluent shoulder of the $\mathrm{Pb} \mathrm{L} \beta 2$ peak (Figure 7). The Rb mass fractions are modestly underreported, probably due to unadapted background stripping.
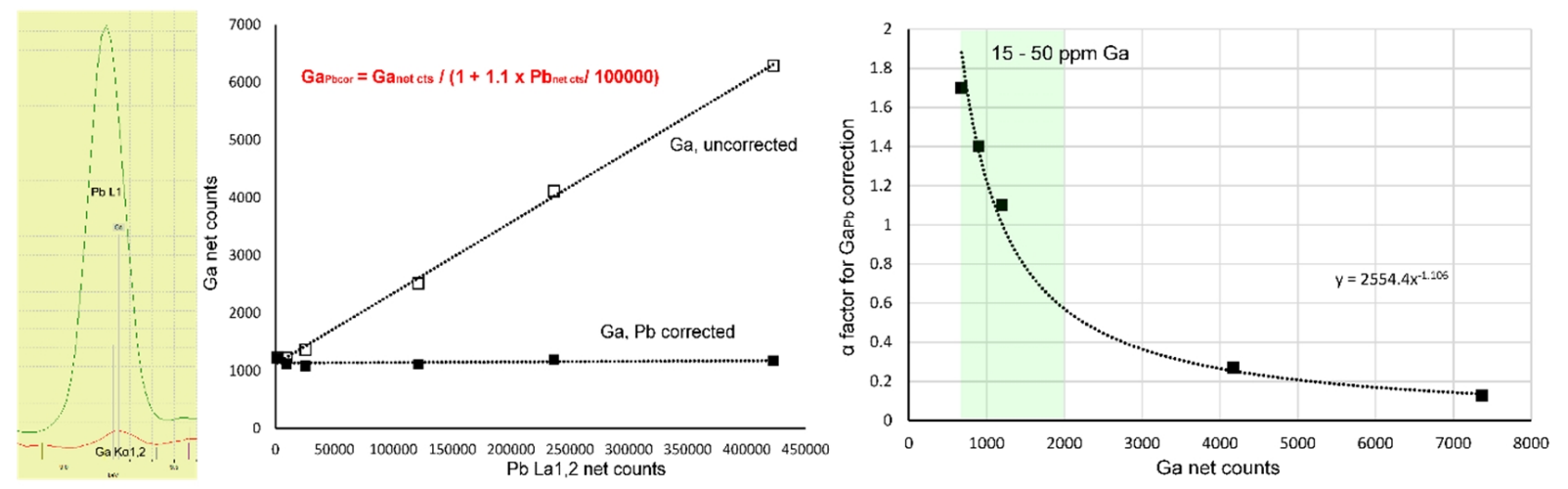

Figure 5. Pb peak overlap correction for Ga. $\alpha$ strongly depends on the Ga concentration in the typical range of pottery (green zone, 15-50 ppm Ga)

$\mathrm{Pb}$ spectral interference could also be corrected with Lachance-Traill algorithms. The empirical $\mathrm{Ga}, \mathrm{Rb}$ and $\mathrm{Y}$ influence coefficients cover both $\mathrm{Pb}$ absorption and $\mathrm{Pb}$ peak overlap. Unlike $\mathrm{Pb}$ absorption, the numerical values ( $\alpha$ factors) of the Lachance-Traill type correction terms for spectral interference, however, are only valid for a narrow concentration range of the effected element. Particularly at low $\mathrm{Ga}$ and $\mathrm{Y}$ mass fractions and high $\mathrm{Pb}$ surface contamination the peak area ratios get 
highly unfavourable, thus adding considerable uncertainty to the overall quantification of these two elements, which in clays and pottery are typically close to the detection limit of energy dispersive XRF.
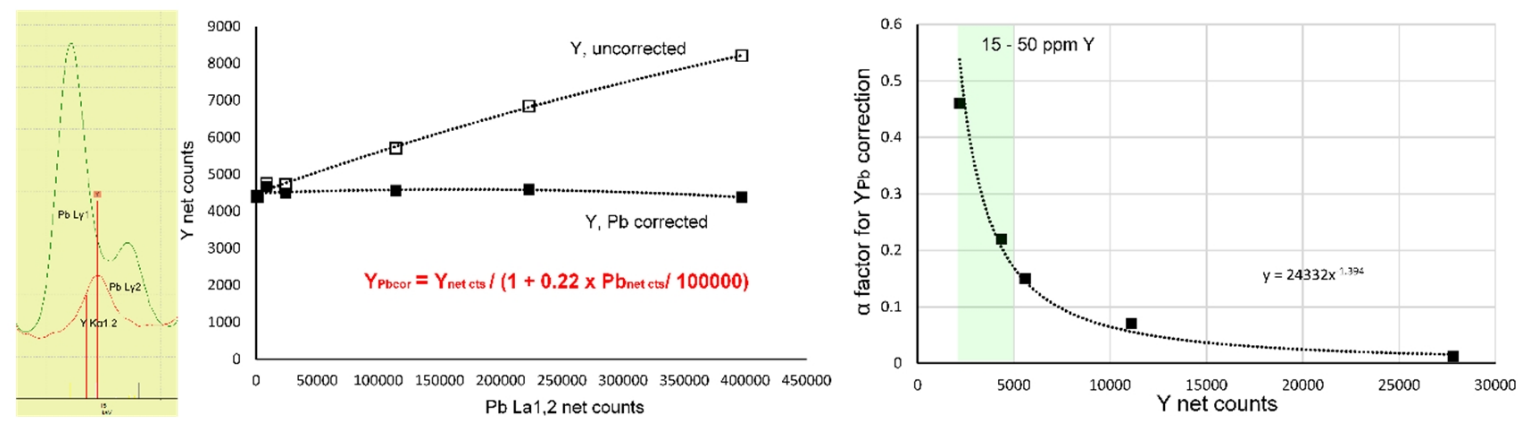

Figure 6. Pb peak overlap correction for $\mathrm{Y} . \alpha$ strongly depends on the $\mathrm{Y}$ concentration in the typical range of pottery (green zone, 15-50 ppm $\mathrm{Y}$ )
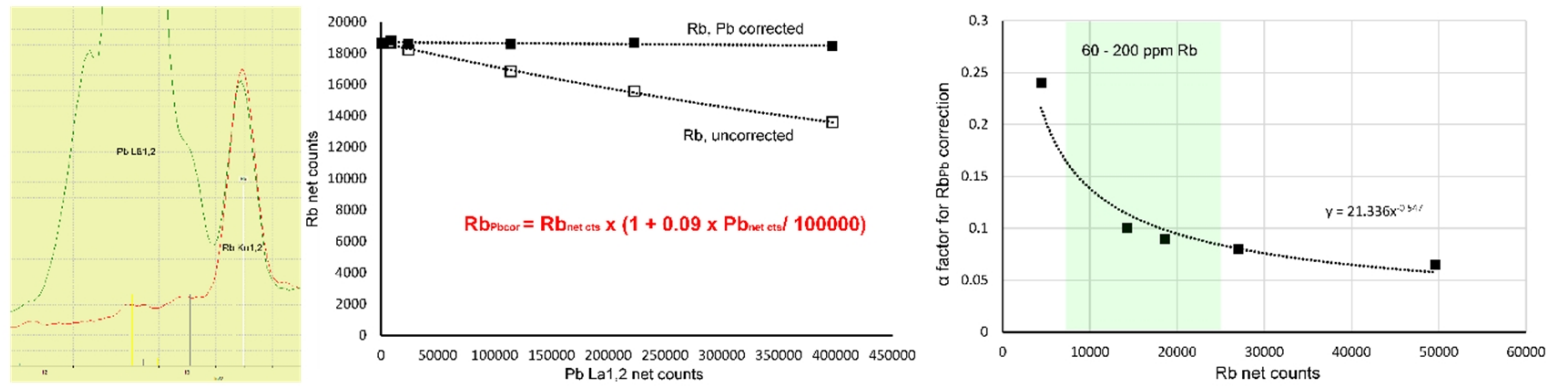

Figure 7. Pb peak overlap correction for Rb. $\alpha$ modestly depends on the Rb concentration in the typical range of pottery (green zone, 60-200 ppm Rb)

Table 1 summarizes the outcome of a successful $\mathrm{Pb}$ matrix absorption correction for $\mathrm{Ti}, \mathrm{Fe}, \mathrm{Sr}, \mathrm{Zr}$ and $\mathrm{Nb}$ as well as for the combined absorption and spectral interference correction for $\mathrm{Ga}, \mathrm{Rb}$ and $\mathrm{Y}$, compared with the uncorrected quantification results.

Table 1. Effect of simulated $\mathrm{Pb}$ surface contamination on accuracy and precision with and without correction of $\mathrm{Pb}$ absorption and spectral interference

\begin{tabular}{|c|c|c|c|c|c|c|c|c|c|}
\hline without $\mathrm{Pb}$ correction & $\mathrm{Pb} \%$ * & $\mathrm{Fe} \%$ & Ga \% & $\mathrm{Nb} \%$ & $\mathbf{R b} \%$ & $\mathrm{Sr} \%$ & $\mathrm{Ti} \%$ & $\mathbf{Y} \%$ & $\mathrm{Zr} \%$ \\
\hline Surface Pb-0 (blank) & 0.00 & 1.37 & 0.0026 & 0.0025 & 0.0145 & 0.0090 & 0.812 & 0.0040 & 0.0299 \\
\hline Surface Pb-1 & 0.01 & 1.43 & 0.0027 & 0.0025 & 0.0148 & 0.0092 & 0.828 & 0.0042 & 0.0309 \\
\hline Surface $\mathrm{Pb}-2$ & 0.06 & 1.40 & 0.0031 & 0.0025 & 0.0144 & 0.0090 & 0.805 & 0.0041 & 0.0302 \\
\hline Surface $\mathrm{Pb}-3$ & 0.25 & 1.39 & 0.0049 & 0.0024 & 0.0135 & 0.0089 & 0.759 & 0.0048 & 0.0298 \\
\hline Surface $\mathrm{Pb}-4$ & 0.36 & 1.35 & 0.0060 & 0.0022 & 0.0132 & 0.0089 & 0.747 & 0.0052 & 0.0302 \\
\hline Surface $\mathrm{Pb}-5$ & 0.69 & 1.22 & 0.0096 & 0.0022 & 0.0117 & 0.0084 & 0.607 & 0.0060 & 0.0278 \\
\hline Surface $\mathrm{Pb}-6$ & 1.12 & 1.14 & 0.0138 & 0.0020 & 0.0108 & 0.0085 & 0.520 & 0.0072 & 0.0272 \\
\hline Mean & - & 1.33 & 0.0061 & 0.0023 & 0.0133 & 0.0088 & 0.725 & 0.0051 & 0.0294 \\
\hline$\%$ RSD & - & 8.15 & 68.22 & 8.86 & 11.23 & 3.47 & 16.12 & 23.13 & 4.65 \\
\hline with $\mathrm{Pb}$ corretion & $\mathrm{Pb} \%$ * & $\mathrm{Fe} \%$ & Ga \% & $\mathrm{Nb} \%$ & $\mathbf{R b} \%$ & $\mathrm{Sr} \%$ & $\mathrm{Ti} \%$ & $\mathbf{Y} \%$ & $\mathrm{Zr} \%$ \\
\hline Surface $\mathrm{Pb}-0$ (blank) & 0.00 & 1.37 & 0.0026 & 0.0025 & 0.0145 & 0.0090 & 0.814 & 0.0040 & 0.0299 \\
\hline Surface Pb-1 & 0.01 & 1.44 & 0.0026 & 0.0025 & 0.0148 & 0.0092 & 0.833 & 0.0041 & 0.0310 \\
\hline Surface $\mathrm{Pb}-2$ & 0.06 & 1.42 & 0.0026 & 0.0025 & 0.0147 & 0.0091 & 0.829 & 0.0040 & 0.0304 \\
\hline Surface $\mathrm{Pb}-3$ & 0.25 & 1.47 & 0.0026 & 0.0025 & 0.0145 & 0.0091 & 0.857 & 0.0041 & 0.0307 \\
\hline Surface $\mathrm{Pb}-4$ & 0.36 & 1.46 & 0.0026 & 0.0024 & 0.0147 & 0.0092 & 0.886 & 0.0042 & 0.0315 \\
\hline Surface $\mathrm{Pb}-5$ & 0.69 & 1.42 & 0.0027 & 0.0024 & 0.0144 & 0.0089 & 0.829 & 0.0040 & 0.0304 \\
\hline Surface $\mathrm{Pb}-6$ & 1.12 & 1.44 & 0.0027 & 0.0023 & 0.0149 & 0.0093 & 0.831 & 0.0040 & 0.0312 \\
\hline Mean & - & 1.43 & 0.0026 & 0.0025 & 0.0147 & 0.0091 & 0.840 & 0.0040 & 0.0307 \\
\hline$\%$ RSD & - & 2.34 & 2.30 & 3.43 & 1.13 & 1.66 & 2.85 & 2.17 & 1.80 \\
\hline
\end{tabular}

* Conversion of $\mathrm{Pb}$ surface net counts into $\mathrm{Pb}$ weight percent is semi-quantitative; ** Relative Standard Deviation in \% 

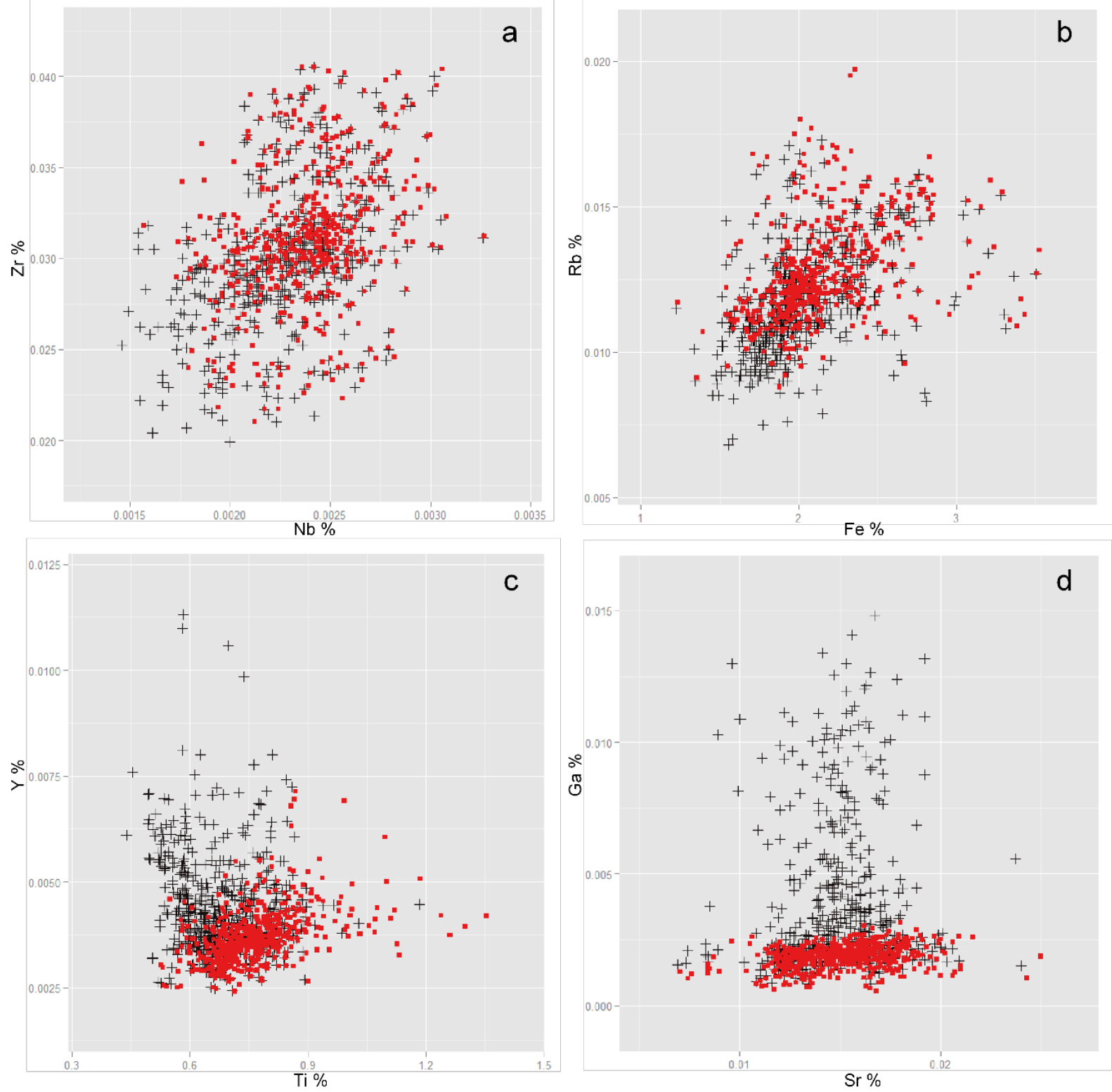

Figure 8. Bivariate scattergrams of element mass fractions with (red squares) and without $\mathrm{Pb}$ absorption and peak overlap correction (black crosses), respectively. Waster sherds $(n=250)$ from a Weser ware workshop at Voelksen, Lower Saxony, Germany, 1600 - 1800

\subsection{Pb Correction of Waster Material}

The proper correction of $\mathrm{Pb}$ and any other matrix and spectral interference effects, is a matter of accuracy of the resulting mass fraction data. However, there is also a practical necessity to remedy such methodological inconsistencies, namely in order to achieve the intended purpose of ceramic provenancing, i.e. the distinction of different production centers. Due to the geochemical nature of the fabric, clay and temper, there is considerable compositional variation within the inventory of a localized production center (a reference group), but only modest differentiation between geographically distant sites [4]. Thus when many reference groups are plotted in bi- or trivariate trace element scattergrams, there is plenty of overlap in the periphery of the individual clusters. Apart from analytical diligence it is therefore mandatory to avoid any methodologically caused scatter intensification which may further enlarge the apparent concentration range of discriminative trace elements in a particular reference group and thus artificially enhance cluster overlap.

In Figure 8 scattergrams of minor and trace elements determined in waster material from a single early modern pottery workshop in Lower Saxony, Germany, are displayed with (red squares) and without $\mathrm{Pb}$ absorption and spectral interference correction (black crosses). The waste material consisted of plain, unglazed earthenware, inside glazed utilitarian ware and inside slipped ware, predominantly dishes and bowls decorated with geometric and/or figurative motives (Weser ware [12], $c f$ Figure 1c), which probably had a broad North-European distribution area to be identified in future provenance studies. $\mathrm{Ti}, \mathrm{Fe}, \mathrm{Sr}, \mathrm{Zr}$ and $\mathrm{Nb}$ are impacted 
by surficial $\mathrm{Pb}$ absorption only, and the effect of absorption correction is just a slight increase of the respective mass fraction values, as evidenced in the $\mathrm{Zr} / \mathrm{Nb}$ scattergram (Figure 8a). Among the elements impacted by $\mathrm{Pb}$ peak overlap a slight increase of the $\mathrm{Rb}$ values can be recognized (Figure $8 b$ ), in line with the distorting effect of the $\mathrm{Pb} L B 2$ shoulder on the background stripping of the Rb Ka1,2 peak. By contrast the $\mathrm{Pb}$ correction effect on the over reported $\mathrm{Y}$ and $\mathrm{Ga}$ concentrations (Figure $8 \mathrm{c}$ and $\mathrm{d}$ ) is highly significant. The cluster density is strongly improved, and the resulting cluster shape is typical for production sites with a restricted number of geochemically closely related clay deposits. In the case of $\mathrm{Ga}$ the mean concentration of the $\mathrm{Pb}$ corrected assemblage is $19 \pm 4 \mathrm{ppm}$, whereas the mean value of the uncorrected file amounts to $38 \pm 28 \mathrm{ppm}$, with erroneous single values, depending on the extent of $\mathrm{Pb}$ contamination, of above $100 \mathrm{ppm}$.

\section{Discussion}

Islamic and Hispano-Moresque lead glazed pottery, Italian archaic and Renaissance majolica, French Saintonge slip ware, Dutch and German slip wares (Werra, Weser and Lower Rhenish decorated pottery) all had a broad distribution beyond their narrow production regions. The North European continental wares are found in archaeological contexts around the North Sea [12-14], and the South European produces in the circum-Mediterranean, but also on the British Isles $[15,16]$. Though the wares can be distinguished stylistically, similar produce, probably under stylistic influence, has been manufactured at different places (e.g. Werra ware, Figure $1 \mathrm{a}, \mathrm{b}$ ), and its provenance cannot be determined by mere art historian stylistic characterization. Archaeologists therefore depend on compositional analysis if they want to hypothesize the production origins and trade routes.

At present micro and portable XRF instruments are the only devices for true non-destructive compositional analysis of ceramics. Thereby the method is still considered as experimental, and its accuracy is frequently questioned, particularly for poor factory calibrations of the portable instruments and lack of validation with certified reference materials [17-21]. Proper calibration is, however, possible with matrix matched reference materials [21] and with spiked fired clay samples in particular [4]. Spiked concentration series are also required for establishing range specific algorithms for correction of spectral interferences, namely of $\mathrm{Rb} / \mathrm{Y}, \mathrm{Y} / \mathrm{Nb}$ and $\mathrm{Sr} / \mathrm{Zr}$ peak overlap. Empirical $\mathrm{Pb}$ absorption and interference correction is thus just an extension of the mandatory calibration and validation effort for quantitative trace element determination of a particular kind of sample material.

\section{Conclusions}

For non-destructive compositional analysis of pottery with lead contaminated surface, empirical correction algorithms have been established which compensate for $\mathrm{Pb}$ absorption as well as $\mathrm{Pb}$ spectral interference of $\mathrm{Ga}, \mathrm{Rb}$ and $\mathrm{Y}$. Applying such correction terms is a prerequisite for accurate quantification of minor and trace elements in lead contaminated ceramic fabrics, and its utility for cluster shape improvement has been demonstrated with waster material of an exemplary early modern pottery production workshop. Whether $\mathrm{Pb}$ absorption and interference correction is necessary and to what extent, is a matter of sophistication of the applied deconvolution algorithms, but without proper check and validation of the quantification software used with the spectrometers erroneous results are bound to occur.

\section{Acknowledgements}

The author thanks Walter Semke (†), Voelksen, Lower Saxony, for providing waster material from his estate for non-destructive analysis, which meanwhile has been forwarded for permanent deposition to the local folk art museum at Springe/ Hannover, Germany.

\section{REFERENCES}

[1] A. M. W. Hunt, On the origin of ceramics: moving toward a common understanding of 'provenance', Archaeological Review from Cambridge 27.1 (2012) 85-97.

[2] H. Mommsen, Provenance determination of pottery by trace element analysis: problems, solutions and applications, J. Radioanal. Nucl. Chem. 247 (2001) 657-662.

[3] P. Degryse, D. Braekman, Elemental and Isotopic Analysis of Ancient Ceramics and Glasses, in: Treatise on Geochemistry, H. D. Holland, K. K. Turekian (Eds.), second edition Vol 14, Archaeology and Anthropology, T. E. Cerling (Ed.), Elsevier-Pergamon, Oxford, 2014, pp. 191-207.

[4] D. Wilke, D. Rauch, P. Rauch, Is non-destructive provenancing of pottery possible with just a few discriminative trace elements? Science and Technology of Archaeological Research 2 (2016) http://dx.doi.org/10.1080/ 20548923.2016.1209030

[5] N. Forster, P. Grave, Effects of elevated levels of lead in ceramics on provenance studies using non-destructive PXRF: a case study in Byzantine Cypriot glazed ceramics, X-Ray Spectrom. 42 (2013) 480-486.

[6] C. Giannotta, C. Laganara, R. Laviano, A. Mangone, A. Traini, Medieval Islamic-type pottery from Siponto (Italy): an integrated physical-chemical and mineralogical investigation, X-Ray Spectrom. 35 (2006) 338-346.

[7] M. Salim, Y. Munekage, lead removal from aqueous solution using silica ceramic: adsorption kinetics and equilibrium studies, Int. J. Chemistry 1 (2009) 23-30.

[8] S. Ahmad, A. Ali, A. Ashfaq, Equilibrium, kinetics and thermodynamic study of $\mathrm{Pb}$ (II) ions from aqueous solution by using fired ceramic, Int. J. Scientific Research Modern 
Education 1 (2016) 231-245.

[9] A. Bruijn, Spiegelbeelden - Werra-keramiek uit Enkhuizen 1605, Stichting Promotie Archeologie, Zwolle, 1992.

[10] P. J. Potts, P.C. Webb, O. Williams-Thorpe, Investigation of a correction procedure for surface irregularity effects based on scatter peak intensities in the field analysis of geological and archaeological rock samples by portable X-ray fluorescence spectrometry, J. Anal. Atomic Spectrom. 12 (1997) 769-776.

[11] G. R. Lachance, Correction procedures using influence coefficients in X-ray fluorescence spectrometry, Spectrochim. Acta 48B (1993) 343-357.

[12] H.-G. Stephan, Die bemalte Irdenware der Renaissance in Mitteleuropa, Deutscher Kunstverlag, München, 1987.

[13] J. G. Hurst, D.S. Neal, H. J. E. van Beuningen, Pottery produced and traded in North-West Europe 1350-1650, Rotterdam Paper VI, Museum Boymans-van Beuningen, Rotterdam, 1986

[14] J. Chapelot, The Saintonge pottery industry in the later Middle Ages, in: Ceramics and Trade, P. J. Davey, R. Hodges (Eds.), University of Sheffield, Sheffield, 1983, pp. 49-53.

[15] H. Blake, Medieval pottery: Technical innovation or economic change? In: Papers in Italian archaeology I: the Lancaster Seminar, Recent research in prehistoric, classical and medieval archaeology Part ii, H. Blake, T. W. Potter, D. W. Whitehouse (Eds.), BAR Supplementary Series 41(ii), 1978, pp. $435-474$

[16] J. G. Hurst, Spanish pottery imported into medieval Britain, Medieval Archaeology 21 (1977) 68-105.

[17] G. E. M. Hall, G. F. Bonham-Carter, A. Buchar, Evaluation of portable X-ray fluorescence ( $\mathrm{XXRF)}$ in exploration and mining: Phase I, control reference materials, Geochemistry: Exploration, Environment, Analysis 14, 2 (2014) 99-123.

[18] N.W. Brand, C. J. Brand, Performance comparison of portable XRF instruments, Geochemistry: Exploration, Environment, Analysis 14, 2 (2014) 125-138.

[19] S. J. Piercey, M.C. Devine, Analysis of powdered reference materials and known samples with a benchtop, field portable X-ray fluorescence (pXRF) spectrometer: evaluation of performance and potential applications for exploration lithogeochemistry, Geochemistry: Exploration, Environment, Analysis 14,2 (2014) 139-148.

[20] R. M. Conrey, M. Goodman-Elgar, N. Bettencourt, A. Seyfarth, A. Van Hoose, J.A. Wolff, Calibration of a portable $\mathrm{X}$-ray fluorescence spectrometer in the analysis of archaeological samples using influence coefficients, Geochemistry: Exploration, Environment, Analysis 14,3 (2014) 291-301.

[21] A. M. W. Hunt, R.J. Speakman, Portable XRF analysis of archaeological sediments and ceramics, J. Archaeol. Sci.53 (2015) 626-638. 